\title{
Metabolic syndrome in overweight children from the city of Botucatu - São Paulo State - Brazil: agreement among six diagnostic criteria
}

\author{
Ana Elisa M Rinaldi*1,2, Gustavo D Pimentel2,3, Avany F Pereira4, Gleice FCP Gabriel5, Fernando Moreto2,6 and \\ Roberto C Burini2,7
}

\begin{abstract}
Background: The metabolic syndrome has been described in children; however, a standard criterion has not been established for its diagnosis. Also, few studies have been conducted to specifically observe the possible existence of agreement among the existing diagnostic criteria. The purpose of the study is to evaluate agreement concerning prevalence rates of the metabolic syndrome diagnosed by six different criteria in overweight schoolchildren in the city of Botucatu - SP -Brazil.

Methods: This is a cross-sectional study on 128 overweight schoolchildren. Clinical examination included anthropometry, pubertal staging evaluation, and blood pressure. Triacylglycerol, glycemia, HDL-cholesterol, insulin levels, and HOMA-IR were determined. The Kappa index, the Mann-Whitney test and the chi-square test were used for statistical analysis.

Results: The prevalence of the metabolic syndrome varied from 10 to $16.5 \%$ according to different diagnostic criteria. Results were similar for boys and girls and pubertal stage. Great agreement was observed among the six different diagnostic criteria for the metabolic syndrome.

Conclusions: Different diagnostic criteria, when adopted for subjects with similar demographic characteristics, generate similar and compatible prevalence. Results suggest that it is possible to adopt any of the analyzed criteria, and the choice should be according to the components available for each situation.
\end{abstract}

\section{Background}

Insulin resistance was firstly described by Reaven (1988) [1] as the concomitant presence of abdominal adiposity, dyslipidemia, hypertension and insulin resistance or type- 2 diabetes mellitus, and it is regarded as the main risk factor for cardiovascular diseases.

The term syndrome was firstly used to describe a set of risk factors utilized by a group of researchers whose main focus was diabetes mellitus [2]. Reaven (1988) [1] described syndrome $\mathrm{X}$ as a cluster of factors such as abdominal adiposity, dyslipidemia, hypertension and insulin resistance, emphasizing the role played by the latter as a possible precursor factor for the other diseases.

\footnotetext{
* Correspondence: anaelisarinaldi@gmail.com

1 Uberlândia School of Medicine, Nutrition Course, Uberlândia Federal University - UFU, Uberlândia, MG, Brazil

Full list of author information is available at the end of the article
}

That syndrome was called by other researchers as the insulin resistance syndrome, concentrating the discussion on diabetes mellitus and hyperinsulinemia as possible causal factors and disregarding overweight [3,4]. Later, the Adult Treatment Panel III -National Cholesterol Education Program (ATPIII-NCEP) began to refer to that syndrome as the metabolic syndrome, with the purpose to use the term in the more global context and consider other causal factors related with abdominal fat excess [5].

Several studies [6-8] have evaluated the prevalence of the metabolic syndrome in children or the isolated presence of its components, despite the inexistence of a single diagnostic criterion. Disagreement concerning the choice for the best diagnostic criterion mainly results from the difficulty in establishing cutoff points due to the absence of clinical manifestations of cardiovascular diseases in childhood [9]. There are doubts whether cutoff points 
must be absolute or expressed in percentiles considering age, gender and pubertal stage due to rapid growth in childhood and mainly in adolescence [10].

As regards the prevalence of the metabolic syndrome at this age range, data disagree according to the region, diagnostic criteria and cutoff points adopted. In a population-based study, the prevalence of the metabolic syndrome in American adolescents was 4.2\% for the general sample and $28.7 \%$ among overweight individuals [8]. Cruz et al. (2004) [11] found a 30\% rate for the metabolic syndrome in obese children and adolescents by adopting another similar criterion to that previously cited; however, that was achieved by fixing the cutoff points in percentiles according to age and gender.

In Spain [12], the prevalence of the metabolic syndrome was $18 \%$ among obese children and adolescents. It was a similar result to that observed in a French study, which found $15.9 \%$ [13]. Nevertheless, in the National Chinese Study on Health and Nutrition with a representative sample of children and adolescents, prevalence was $1.5 \%$ in eutrophic, $18.3 \%$ in overweight and $38.1 \%$ in obese subjects [14].

In Brazil, data concerning the metabolic syndrome in childhood are available from regional studies. Those including overweight children and adolescents observed a prevalence rate for the metabolic syndrome from 4 to $42.4 \%$ [15-18]. The diagnostic criteria used in the studies were those proposed by the National Cholesterol Education Program (NCEP) [5] and WHO (1998) [19] with adaptations for age and cutoff points.

Despite the large number of studies available on the prevalence of the metabolic syndrome in the pediatric population, few have been conducted to specifically observe the possible existence of agreement among diagnostic criteria, and studies of this type only show its variation when different criteria are adopted [20,21].

This study aimed at analyzing agreement concerning the prevalence of the metabolic syndrome as diagnosed by six different criteria in overweight schoolchildren in the city of Botucatu, São Paulo State - Brazil.

\section{Methods}

This is a cross-sectional study conducted in three primary schools (private, public and non-governmental) in Botucatu/SP - Brazil from June to December 2007. The schools were selected based on approval by their principals and from the city's Secretary of Education.

The study was approved by the Research Ethics Committee of the Botucatu School of Medicine - UNESP, according to official letter number $579 / 2006$, as well as by that of the Faculty of Pharmaceutical Sciences - USP, according to document number 78/2007. All persons responsible for the schools and the schoolchildren signed a free consent form designed in accordance with resolu- tion no. 196/96 concerning "Studies involving human beings, by the Health Council of the Ministry of Health".

Initially, anthropometric and blood pressure measurements were performed on all 6-to-10-year-old schoolchildren (670 children) enrolled in the three schools. Later, those diagnosed as overweight (231 children), as defined by a body mass index (BMI) equal to or higher than the $85^{\text {th }}$ percentile, based on the reference curves developed by the National Center for Health Statistics - Center for Disease Control and Prevention (CDC, 2000) [22], were selected.

The nutritional diagnosis of overweight (BMI equal to or higher than the $85^{\text {th }}$ percentile and lower than the $95^{\text {th }}$ percentile) and/or obesity (BMI equal to or higher than the $95^{\text {th }}$ percentile) according to age and gender (CDC, 2000) [22] and the performance of the biochemical tests proposed were considered as criteria for inclusion in the study. The overweight schoolchildren with a clinical history of other morbidities and undergoing medical treatment and clinical-nutritional follow-up for body weight reduction were excluded.

All the children with an overweight/obesity diagnosis were contacted by telephone in order to participate in the study. Sample size estimation was based on the prevalence of overweight and obesity (18\%) of this sample by adopting a 7\% margin of error. Therefore, the minimum number of subjects was 115 children.

Body weight was measured by an electronic scale (Filizola') to the nearest $0.1 \mathrm{~kg}$ while the schoolchildren were barefoot and wearing light clothes. Height was determined by a portable Seca stadiometer to the nearest 01.cm, according to norms proposed by the World Health Organization (WHO, 1995) [23]. BMI (weight in kilograms divided by the squared height in meters) was calculated by using the measured height and weight and converted to percentiles for age in months and gender by using the Center for Disease Control and Prevention (CDC, 2000) [22] growth charts and computer software Epi-Info version 3.2 (2004). Waist circumference (WC) was measured midway between the rib cage and the superior border of the iliac crest by using a millimetric non-extensible and non-elastic measuring tape (Sanny) after complete expiration.

The triceps (TSF) and subscapular (SSSF) skinfold thicknesses were measured three times to the nearest 1.0 $\mathrm{mm}$ on the right side of the body by Lange Skinfold calipers (Cambridge Scientific Industries, Inc, Cambridge, $\mathrm{MD})$, and the mean values were used in the analyses. The triceps skinfold was then measured parallel to the long axis of the arm midway between the acromion and the olecranon, with the arm slightly flexed, and the subscapular skinfold was measured below the lower angle of the left scapula at a diagonal in the natural cleavage of the 
skin. Fat mass was calculated from skinfold thickness measurements by using age and gender-specific equations proposed by Slaughter et al. (1988) [24]. The reference values adopted for body fat percentage were proposed by Lohman (1987) [25], and values equal to or higher than $25 \%$ for girls and equal to or higher than $20 \%$ for boys were classified as mildly high.

Blood pressure was measured by the auscultatory method after the child had been sitting at rest for a minimum period of 5 minutes, and the cuff involved $80 \%$ of the right arm's circumference. The arm rested on a support surface at the level of the precordium. Three variable cuff sizes were used according to the child's brachial circumference. Blood pressure was measured three times in three different days only when the first measurement was above 95th percentile according to gender, age and height, based on The Fourth Report on the Diagnosis, Evaluation, and Treatment of High Blood Pressure in Children and Adolescents [26].

Fasting glucose, HDL-cholesterol and triacylglycerol concentrations were quantified by using a semi-automatic spectrophotometer (Labquest', Labtest Diagnóstica) and commercial kits (Labtest Diagnóstica) by the enzymatic colorimetry method. The serum aliquots were stored at a temperature of $-80^{\circ} \mathrm{C}$ for later insulin analysis by the immunochemical luminescence method using commercial kits (DPC Medlab) and an automated device (Immulite 2000 DPC Medlab). HOMA-IR (Homeostasis Model Assessment-Insulin Resistance) was calculated according to the formula: fast insulin (UI/L) $\mathrm{x}$ fast glyce$\mathrm{mia}(\mathrm{mmol} / \mathrm{L}) / 22.5$, as proposed by Levy et al (1998) [27].

Pubertal stage was assessed in all children by a pediatrician using the 5-stage scale for breast development and pubic hair in girls; testicular size and pubic hair in boys, according to Tanner (1962) [28]. The children were thereafter categorized into 3 groups: prepubertal (Tanner stage 1), pubertal (Tanner stage 2-4) and postpubertal (Tanner stage 5).

These criteria were selected because their components could be easily obtained and because they presented cutoff points that were already adapted to the pediatric age range. For each selected criterion, the reference values established by their respective authors (Table 1) were respected. The metabolic syndrome diagnosis was established, in all criteria, by the presence of three or more altered components.

After of the evaluations, the children's parents received the results (anthropometric assessment, biochemical tests and blood pressure). All the children were given nutritional advice, and those with a diagnosis for high blood pressure were referred to the pediatric nephrology outpatient unit of the Botucatu School of Medicine, Brazil.
The data were processed in software SPSS version 12.0 (SPSS Inc., Chicago, IL, USA). Data normality was evaluated by the Shapiro-Wilk Test. Descriptive statistics are displayed as arithmetic means and standard deviation. Comparison between genders for the anthropometric and biochemical data was performed by the Mann-Whitney Test. Agreement among the six different criteria was evaluated by the Kappa Index, which expresses the consistency or agreement of results when measurement or examination is repeated in identical conditions. The interpretation of results was based on the following intervals: smaller than zero, poor; from 0.00 to 0.20 , little; from 0.21 to 0.40 , reasonable; from 0.41 to 0.60 , moderate; from 0.61 to 0.80 , substantial and from 0.80 to 1.00 , almost perfect [29]. The Wilcoxon test was used to compare the number of altered components in each criterion. The possible influence of gender, pubertal staging, nutritional status diagnosis by BMI (overweight and obesity) and body fat percent of the metabolic syndrome was tested by the Chi-square or Fischer's exact test. P values 0.05 were considered statistically significant.

\section{Results}

After the schoolchildren's $(\mathrm{N}=670)$ anthropometric assessment, overweight prevalence was observed in 33\% of the sample ( $16.1 \%$ overweight and $17.7 \%$ obesity), with a proportion of obese/overweight to eutrophic individuals of 1:3. Of the overweight schoolchildren participating in the present study $(\mathrm{n}=128), 44 \%(\mathrm{n}=56)$ showed overweight, and $56 \%(n=72)$ showed obesity, with a proportion of obese/overweight individuals of 1:1. Boys showed greater alterations in BMI (percentile), mean glycemia levels and systolic pressure (Table 2). As regards pubertal stage, $67 \%$ of the schoolchildren were classified as prepubertal, 33\% pubertal and none as postpubertal (data not shown).

The prevalence of the metabolic syndrome varied from 10 to $16.5 \%$. The percent of altered components was more frequent in obese children according to the criteria proposed by Ferreira et al (2007) [15], Silva et al (2005) [16], Monzavi et al (2006) [30] and Cook et al (2003) [8] $(\mathrm{p}<0.05)$ and in individuals with high body fat percents according to the criteria proposed by Ferreira et al (2007) [15], Silva et al (2005) [16], Monzavi et al (2006) [31] and Cook et al (2003) [8]; however, there was no influence from gender or pubertal staging (Figure 1).

Anthropometric indicators (BMI and WC), triacylglycerols, HDL-C, HOMA-IR, blood pressure and glycemia constituted the decreasing sequence of prevalences of altered components in the criteria adopted (Table 3).

The percent of zero or one of the syndrome's altered components was significantly higher among overweight children while the percent of two or more altered compo- 
Table 1: Description of the metabolic syndrome criteria and their respective cutoff points.

Metabolic syndromecriteria

\begin{tabular}{|c|c|c|c|c|c|c|}
\hline Age group of children in the studies & 7-11 years & 10-19 years & $6-11$ years & $8-12$ years & $8-16$ years & $12-19$ years \\
\hline Metabolic syndrome components & Ferreira et al 15 & Silva et al ${ }^{16}$ & Boney et at ${ }^{30}$ & Braunschweig et al 7 & Monzavi et al31 & Cook et al ${ }^{8}$ \\
\hline Anthropometric indicators* & $\mathrm{BMI} \geq 95^{\text {th }}$ percentile & $\mathrm{BMI} \geq 97^{\text {th }}$ percentile & $\mathrm{IMC} \geq 85^{\text {th }}$ percentile & $W C \geq 90^{\text {th }}$ percentile & $\mathrm{BMI} \geq 95^{\text {th }}$ percentile & $W C \geq 90^{\text {th }}$ percentil \\
\hline Insulin resistance indicators ${ }^{* *}$ & Glycemia $>100$ & HOMA $>2.5$ & Glycemia >110 & Glycemia $\geq 110$ & Glycemia $\geq 100$ & Glycemia $\geq 100$ \\
\hline $\mathrm{HDL}-\mathrm{C}(\mathrm{mg} / \mathrm{dL})$ & $\leq 38$ & $\leq 35$ & $<5^{\text {th }}$ percentile & $\leq 40$ & $\leq 10^{\text {th }}$ percentile & $\leq 40$ \\
\hline Triglycerides (mg/dL) & $\geq 110$ & $\geq 130$ & $>95^{\text {th }}$ percentile & $\geq 110$ & $\geq 90^{\text {th }}$ percentile & $\geq 110$ \\
\hline $\mathrm{SBP} / \mathrm{DBP}(\mathrm{mmHg})$ & $>95^{\text {th }}$ percentile & $\geq 95^{\text {th }}$ percentile & $>95^{\text {th }}$ percentile & $\geq 90^{\text {th }}$ percentile & $\geq 90^{\text {th }}$ percentile & $\geq 90^{\text {th }}$ percentile \\
\hline
\end{tabular}

${ }^{*} \mathrm{BMI}=$ body mass index or $\mathrm{WC}=$ waist circumference ${ }^{* *}$ impaired fasting glucose/HOMA-IR 
Table 2: Anthropometric and biochemical characteristics of school children according to gender. Botucatu-SP, 2007.

\begin{tabular}{|c|c|c|c|}
\hline Variables & General & Boys & Girls \\
\hline & $n=128$ & $n=58$ & $n=70$ \\
\hline Age (years) & $8.1 \pm 1.4$ & $8.1 \pm 1.4$ & $8.1 \pm 1.4$ \\
\hline Height (m) & $1.3 \pm 0.1$ & $1.3 \pm 0.1$ & $1.3 \pm 0.1$ \\
\hline Weight (kg) & $41.3 \pm 11.1$ & $42.9 \pm 12.3$ & $40.0 \pm 10.0$ \\
\hline BMI (kg/m 2) & $22.2 \pm 3.2$ & $22.6 \pm 3.6$ & $21.8 \pm 2.7$ \\
\hline BMI (percentile) & $94.3 \pm 4.3$ & $95.3 \pm 3.9^{a}$ & $93.4 \pm 4.5^{b}$ \\
\hline$W C(\mathrm{~cm})$ & $72.1 \pm 9.8$ & $74.0 \pm 11.1^{\mathrm{a}}$ & $70.6 \pm 8.4^{b}$ \\
\hline TSF $(\mathrm{mm})$ & $20.3 \pm 4.7$ & $20.2 \pm 4.8$ & $20.4 \pm 4.7$ \\
\hline $\mathrm{SSF}(\mathrm{mm})$ & $14.7 \pm 5.8$ & $14.6 \pm 6.3$ & $14.8 \pm 5.3$ \\
\hline$\% B F$ & $28.9 \pm 6.5$ & $29.5 \pm 7.5$ & $28.4 \pm 5.6$ \\
\hline Glycemia (mg/dL) & $83.7 \pm 6.5$ & $85.6 \pm 5.9^{a}$ & $82.1 \pm 6.6^{b}$ \\
\hline $\mathrm{HDL}-\mathrm{C}(\mathrm{mg} / \mathrm{dL})$ & $47.8 \pm 10.9$ & $47.5 \pm 9.7$ & $48.0 \pm 11.9$ \\
\hline Insulin $(\mu \mathrm{U} / \mathrm{mL})$ & $7.6 \pm 5.6$ & $7.0 \pm 4.7$ & $8.2 \pm 6.2$ \\
\hline HOMA-IR & $1.6 \pm 1.2$ & $1.5 \pm 1.0$ & $1.6 \pm 1.3$ \\
\hline TG (mg/dL) & $98.0 \pm 51.4$ & $99.7 \pm 56.6$ & $96.5 \pm 47.0$ \\
\hline $\mathrm{SBP}(\mathrm{mmHg})$ & $98.9 \pm 12.1$ & $101.3 \pm 13.6$ & $96.9 \pm 10.5$ \\
\hline $\mathrm{DBP}(\mathrm{mmHg})$ & $63.9 \pm 8.4$ & $64.9 \pm 9.4$ & $63.2 \pm 7.5$ \\
\hline
\end{tabular}

Different letters indicate significant difference between genders $(p<0.05)$. BMI: body mass index; WC: waist circumference; TSF: triceps skinfold, SSF: subscapular skinfold, \%BF: percentage body fat; HOMA-IR: Homeostasis Model Assessment-Insulin Resistance; TG: triglycerides; SBP: systolic blood pressure; DBP: diastolic blood pressure.

nents was higher in obese children $(\mathrm{p}<0.05)$ for all criteria. No children showed altered fast glycemia according to the criteria proposed by Boney et al (2005) [31] and Braunschneig et al (2005) [7], and only one showed abnormal values according to the criteria proposed by Cook et al (2003) [8], Monzavi et al (2006) [30] and Ferreira et al (2007) [15].

For all criteria, the cutoff points for blood pressure, HDL-C and triacylglycerols were similar, a fact that explains the absence of significant difference between the prevalence of alteration in these components according to the six criteria analyzed. Based on this information, it can be assumed that the differences in the prevalence of the metabolic syndrome found among the different criteria were mainly due to anthropometric indicators (BMI or WC) and to the glucose metabolism (HOMA-IR or fasting glycemia) (Table 3 ).

All the criteria agreed among each other, and the Kappa indexes generated values classified as moderate to almost perfect. Perfect agreement was observed among the criteria proposed by Cook et al (2003) [8] vs. Braunschneig et al (2005) [7] and Cook et al (2003) [8] vs. Ferreira et al (2007) [15]. Such result can be explained by the fact that the three criteria have been adapted from that proposed by NCEP-ATPIII with different cutoff-point adaptations.
The criteria showing the least agreement among each other were those proposed by Silva et al (2005) [16] vs. Boney et al (2005) [31], with a Kappa index of 0.53, considered to be moderate agreement (Table 4).

In these subjects, the prevalence of the metabolic syndrome, according to different criteria, showed good agreement. In the same group of subjects, the percent of children diagnosed with the metabolic syndrome seems to show little variance in function of the diagnostic criterion adopted.

\section{Discussion}

Divergent metabolic-syndrome diagnoses at the pediatric age range encouraged the development of this Brazilian study, which is one of the first to evaluate its prevalence agreement according to different diagnostic criteria. The prevalence of the metabolic syndrome varied according to the criteria adopted; however, moderate to perfect agreement was observed among all criteria. Such criteria $[7,8,15,16,30,31]$ were selected because the components used were easy to obtain and because they were applied to a similar age range to that in this study, except for the criterion proposed by Silva et al (2005) [16] and Cook et al (2003) [8]. The latter was selected because recent literature reviews $[32,33]$ have shown it to be the most fre- 


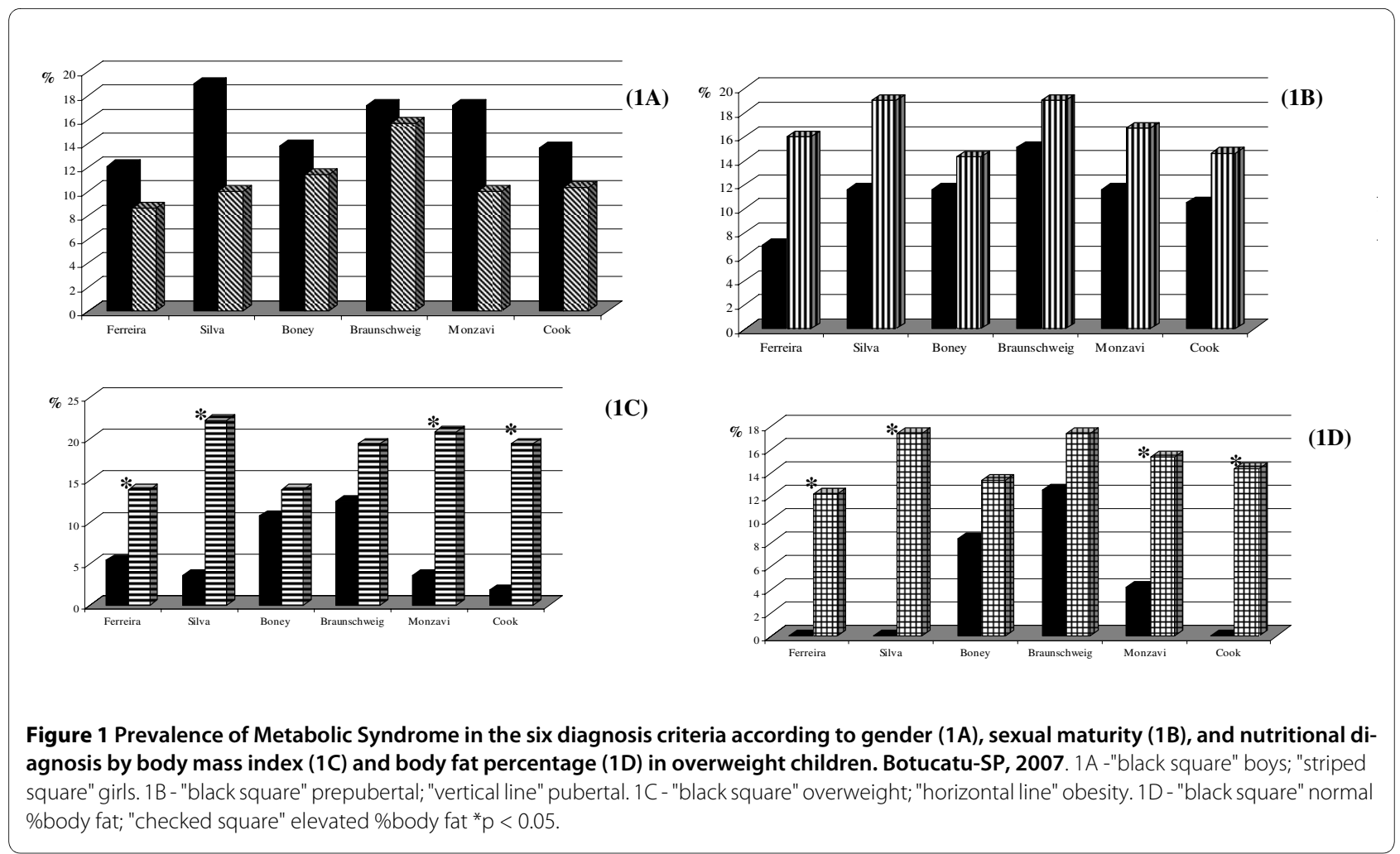

quently used criterion, regardless of age range. This is certainly due to the fact that it is based on NCEP-ATPIII, which is already well founded among adults. Most of the articles available in the literature include adolescents or children in late childhood [8,34-36]. The other criteria, Silva et al (2005) [16], were selected because this study included Brazilian adolescents.

Although the six diagnostic criteria used differed in relation to the cutoff points for each component, there is agreement with regard to including indicative parameters for glycemic (fasting glycemia and HOMA-IR) and lipid (triacylglycerols, HDL-C) abnormalities, one anthropometric indicator (BMI or WC) and blood pressure. In this study, it can be observed that the components mostly contributing to prevalence variation in the metabolic syndrome were the inclusion of BMI or WC and the cutoff point adopted for each of them as well as the choice for glycemia or HOMA-IR. The other components use very similar cutoff points. Such findings are in agreement with the analysis by Brambilla et al (2007) [37] in a review study showing different prevalences according to several diagnostic criteria.

Table 3: Percentage of overweight children with altered metabolic syndrome components according to the six diagnosis criteria.

\section{Diagnostic criteria}

\section{Altered metabolic syndrome $\quad$ Ferreira et al ${ }^{15}$ Silva et al ${ }^{16}$ Boney et al ${ }^{30}$ Braunschweig et al ${ }^{26}$ Monzavi et al ${ }^{31}$ Cook et al components}

\begin{tabular}{|c|c|c|c|c|c|c|}
\hline Adiposity indicators* & $57.8(74)^{* * *}$ & $40.6(52)$ & $100.0(128)$ & $96.1(123)$ & $57.8(74)$ & $45.3(58)$ \\
\hline Insulin resistance indicators ${ }^{* *}$ & $0.8(1)$ & $18.0(23)$ & $0.0(0)$ & $0.0(0)$ & $0.8(1)$ & $0.8(1)$ \\
\hline HDL-C & $19.5(25)$ & $10.9(14)$ & $15.6(20)$ & $25.0(32)$ & $27.3(35)$ & $25.0(32)$ \\
\hline Triacylglycerol & $26.8(34)$ & $16.4(21)$ & $29.7(38)$ & $26.6(34)$ & $30.5(39)$ & $26.6(34)$ \\
\hline SBP/DBP & $11.8(15)$ & $12.5(16)$ & $11.8(15)$ & $14.8(19)$ & $14.8(19)$ & $14.8(19)$ \\
\hline Metabolic syndrome (\%) & $11.7(15)$ & $14.1(18)$ & $12.5(16)$ & $16.4(21)$ & $13.3(17)$ & $11.5(15)$ \\
\hline
\end{tabular}

*BMI: body mass index/Waist circumference; **Fast glycemia/HOMA-IR; ***The number in all parenthesis represents the number of the children with altered metabolic syndrome components SBP/DBP (sistolic blood pressure or diastolic blood pressure). 
Table 4: Agreement (Kappa index) among de metabolic syndrome prevalences according to six different diagnostic criteria.

\begin{tabular}{ccc}
\hline Criteria & Kappa Index & $\boldsymbol{p}$ \\
\hline Ferreira $\times$ Silva & 0.67 & $<0.001$ \\
Ferreira $\times$ Boney & 0.73 & $<0.001$ \\
Ferreira $\times$ Braunschweig & 0.73 & $<0.001$ \\
Ferreira $\times$ Monzavi & 0.70 & $<0.001$ \\
Ferreira $\times$ Cook & $0.84^{*}$ & $<0.001$ \\
Silva $\times$ Boney & 0.53 & $<0.001$ \\
Silva $\times$ Braunschweig & 0.61 & $<0.001$ \\
Silva $\times$ Monzavi & 0.64 & $<0.001$ \\
Silva $\times$ Cook & 0.69 & $<0.001$ \\
Boney $\times$ Braunschweig & 0.78 & $<0.001$ \\
Boney $\times$ Monzavi & 0.62 & $<0.001$ \\
Boney $\times$ Cook & 0.67 & $<0.001$ \\
Braunschweig $\times$ Monzavi & 0.63 & $<0.001$ \\
Braunschweig $\times$ Cook & $0.81^{*}$ & $<0.001$ \\
Monzavi $\times$ Cook & 0.71 & $<0.001$ \\
\hline
\end{tabular}

*perfect concordance

As previously mentioned, the prevalence of the metabolic syndrome in this study varied from 10 to $16.5 \%$, without differences between gender and pubertal staging, as shown by other studies $[7,11,18,20,30,35,38]$. In this investigation, the anthropometric variable was (WC or BMI) the component with the highest percent of alteration, a result which is in accordance with findings in other studies $[7,15,31]$.

As in other investigations, the present study also showed the inexistence, among children at this age range, of altered fasting glycemia. However, Golley et al (2006) [21] point out the importance of analyzing fasting insulinemia, since the number of components of the metabolic syndrome and their prevalence significantly increased according to fasting insulinemia quartiles. Ferreira et al (2007) [15] reported that the higher HOMA-IR tercile, the higher the risk factors for cardiovascular diseases. A Brazilian study conducted on overweight prepubertal children reported that a higher HOMS-IR than 2.5 showed good sensitivity and specificity to detect the metabolic syndrome [38].

Another aspect pointed out in some studies is the need to adapt cutoff points according to age $[20,21]$ Reinehr et al (2007) [17] compared four diagnostic criteria for adults and four for children/adolescents. When using the criteria for adults, prevalence of the metabolic syndrome varied from 6 to 14\%, and among the criteria for children/ adolescents, it ranged from 18 to 39\%. Golley et al (2006)
[21] showed that prevalence in 6-to-9-year-old children according to two criteria for adults was $4 \%$; however, when the same criteria were adjusted according to that age range, prevalence was $39 \%$. The authors also point out that the criteria including total cholesterol and triglycerides and WC can explain most of the prevalence variation in the metabolic syndrome.

The prevalence of the metabolic syndrome found in the present study was similar to that in studies adopted as reference for this investigation, except for the criterion by Monzavi et al (2006) [30], which identified, in their population, a prevalence of $49 \%$. By that criterion, the prevalence of the metabolic syndrome found was $13 \%$, and it can be explained by the higher percent of children with severe obesity in those authors' sample [30].

Agreement among the different criteria varied from moderate to almost perfect. This result was expected since the criteria proposed by Ferreira et al (2007) [15], Braunschneig et al (2005) [7] and Cook et al (2003) [8] are adapted from NCEP-ATPIII for adults; however, with different cutoff points. Seo et al (2008) [36], in a similar study to the present investigation, found great agreement $(88.7 \%)$ among three distinct criteria for the metabolic syndrome in adolescents.

In face of such disparities, the validity of the metabolic syndrome diagnosis is presently being questioned. The same author who firstly defined it has discussed its clinical usefulness since the components are individually treated [39]. Another point of discussion is whether the components of the metabolic syndrome and the diagnosis always have the same importance in assessing the risk for developing cardiovascular diseases and whether the presence of two factors, and not three, would be sufficient to identify a patient at risk [40].

The existing criteria do not seem to be ideal for various reasons, such as: few longitudinal studies allowing for the evaluation of the metabolic syndrome's components from childhood to adulthood have been performed; family history concerning non-transmittable chronic diseases has not yet been thoroughly investigated; few studies have used fast insulinemia as an indicator of the glucose metabolism or cutoff points according to pubertal staging; the inclusion of BMI as an anthropometric indicator may overestimate the prevalence of the metabolic syndrome [40].

With such lack of agreement, some researchers have chosen to use multivariate analysis, for children, with the same components of the metabolic syndrome in adults [10]. Eisenmann (2008) [41] proposed the estimation of a score to diagnose the metabolic syndrome in children including the following components: abdominal circumference, triacylglycerols, HDL-C, blood pressure and glucose intolerance. The great difference in this method is the determination of the $\mathrm{Z}$ individual score for each child 
without dichotomization of variables, thus providing it with greater sensitivity. Recently, Eisenmann et al (2010) [42] analyzed the validity of a continuous metabolic syndrome (cMetS) score derived from principal component analysis based on the criteria by Cook et al (2003) [8] cMetS score 3.72 was the optimal cutoff point with high sensitivity (100\%) and high specificity (94\%), and it meant the highest risk for the metabolic syndrome. However, this method has a major limitation: it is sample-specific.

The main limitation in this study was the absence of a control group consisting of eutrophic children, similarly to other studies $[15,18,30,35]$. The studies including a control group $[11,20,30,34,37]$ showed no or low prevalence of the metabolic syndrome in eutrophic children. The prevalences of the metabolic syndrome may have been overestimated by the larger presence of obese children (56\%) in relation to those overweight. The use of $\mathrm{BMI}$ as a component of the metabolic syndrome in the different criteria may also overestimate its prevalence, a condition described by another study [41].

The importance of this study in clinical practice for the decision concerning the criterion to be used to diagnose the syndrome and in the interpretation of results is noteworthy. Although prevalences differed according to the criterion adopted, agreement among the methods was considered to be satisfactory. The results in the present study can suggest that, in the same group of subjects, children with metabolic abnormalities will be diagnosed regardless of the diagnostic criteria selected.

It can also be speculated that the differences between the cutoff points of the components, namely, blood pressure, triacylglycerols, HDL-C and glycemia, are discreet. As previously discussed, the difference between the criteria is the choice for BMI or WC and fast glycemia or HOMA-IR and which reference to use in order to establish the diagnosis of alteration. Agreement on the use of the best anthropometric and glycidic indicator would reduce prevalence divergences among studies.

Additionally, it is recommended that the glucose, insulin and lipid levels of all children diagnosed with obesity should be periodically observed, and if required, immediate intervention should be made before the metabolic syndrome itself develops [21].

Besides of the metabolic syndrome diagnosis, other factors must be taken into account in cardiovascular risk evaluation in childhood. Dyslipidemia in childhood does not cause adverse health effects, such as acute myocardial infarction, but its long-term effects have been investigated. With the lack or scarcity of longitudinal studies on dyslipidemia in childhood and cardiovascular diseases in adulthood, studies make inferences, and a positive relation is found [43].

The latest recommendation from the American Association of Pediatrics for dyslipidemia screening is the pres- ence of a family history of premature cardiovascular diseases or high total cholesterol concentrations, children whose families have an unknown family history or who have been diagnosed with overweight, obesity, high blood pressure and diabetes mellitus [44]. Several studies have shown a positive correlation between the presence of family history for obesity, systemic high blood pressure, dyslipidemia and type- 2 diabetes mellitus and alteration in the metabolic-syndrome components [45-48].

Low weight at birth also influences the development of chronic diseases in adults, a phenomenon which is referred to as programming [49]. Growth rates in the first weeks of life are critical for later insulin resistance [50]. Fast weight gain soon after birth (0 to 6 months of life) has shown a direct relation with the presence of the metabolic syndrome components in adulthood [51].

The Non-alcoholic fatty liver disease is also related to metabolic disorders, and it is thought to be a result of obesity [52]. Kelishadi et al (2010) [53] have observed that alteration in hepatic enzymes increased with body weight gain, since it was twofold in overweight children and adolescents and fourfold in obese children and adolescents as compared to eutrophic individuals

Hence, an early diagnosis for overweight and the implementation of lifestyle changes are fundamental for preventing, controlling and managing obesity and its associated co-morbidities, such as the metabolic syndrome $[54,55]$.

\section{Conclusions}

Although some authors mentioned the difficulty to compare the prevalence of the metabolic syndrome, this study showed that the six criteria are correlated with each other. The prevalence of the metabolic syndrome varied from 10 to $16.5 \%$ and anthropometric indicators (BMI and WC) were the most altered components in all the criteria adopted. Additionally, the prevalence of the metabolic syndrome is higher in obese individuals as compared to those overweight. Therefore, in the same group of subjects, the prevalence of the metabolic syndrome is similar, regardless of the criterion selected.

\section{List of Abbreviations}

BMI: body mass index; DBP: diastolic blood pressure; HOMA-IR: Homeostasis Model Assessment-Insulin Resistance; NCEP-ATPIII: National Cholesterol Education Program-Adult Treatment Painel III; SBP: systolic blood pressure; SSSF: subscapular skinfold; TSF: triceps skinfold; WC: waist circumference

\section{Competing interests}

The authors declare that they have no competing interests.

\section{Authors' contributions}

AEMR wrote the manuscript and collected the data. GDP corrected the manuscript and performed the statistical analysis. FM and GFCPG collected the data 
and corrected the manuscript. AFP corrected the manuscript. RCB read and approved the final version of the manuscript. All authors read and approved the final manuscript

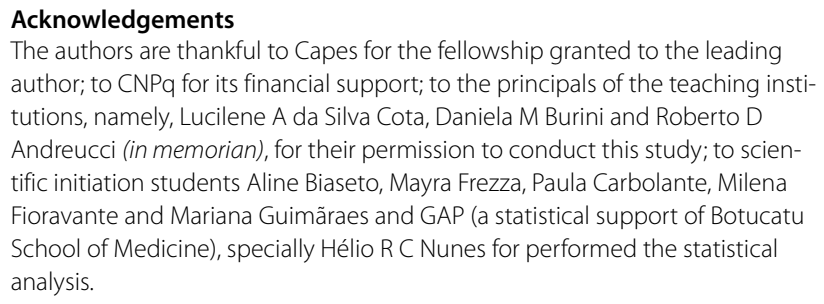
author; to CNPq for its financial support; to the principals of the teaching institutions, namely, Lucilene A da Silva Cota, Daniela M Burini and Roberto D Andreucci (in memorian), for their permission to conduct this study; to scientific initiation students Aline Biaseto, Mayra Frezza, Paula Carbolante, Milena Fioravante and Mariana Guimãraes and GAP (a statistical support of Botucatu School of Medicine), specially Hélio R C Nunes for performed the statistical analysis.

\section{Author Details}

1 Uberlândia School of Medicine, Nutrition Course, Uberlândia Federal University - UFU, Uberlândia, MG, Brazil, 2Exercise and Nutrition Metabolism Center (CeMENutri), Botucatu School of Medicine - UNESP, Botucatu, SP, Brazil, ${ }^{3}$ Department of Physiology, Nutrition Physiology Division - UNIFESP, São Paulo, SP, Brazil, ${ }^{4}$ Department of Nutrition and Dietetics - Rio de Janeiro Federal University - UFRJ, Rio de Janeiro, RJ, Brazil, ${ }^{5}$ Department of Internal Medicine, Course of Physiopathology in Internal Medicine, Botucatu School of Medicine UNESP, Botucatu, SP, Brazil, ${ }^{\circ}$ Department of Pathology, Botucatu School of Medicine - UNESP, Botucatu, SP, Brazil and 'Department of Public Health, Exercise and Nutrition Metabolism Center (CeMENutri), Botucatu School of Medicine - UNESP, Botucatu, SP, Brazil

Received: 25 November 2009 Accepted: 9 June 2010 Published: 9 June 2010

\section{References}

1. Reaven GM: Banting lecture 1988: role of insulin resistance in human disease. Diabetes 1988, 37(12):1595-1607.

2. Grundy SM: Metabolic Syndrome: Connecting and reconciling cardiovascular and diabetes worlds. J Am Coll Cardiol 2006, 47(6):1093-1100.

3. DeFronzo RA, Ferrannini E: Insulin resistance. A multifaceted syndrome responsible for NIDDM, obesity, hypertension, dyslipidaemia, and atherosclerotic cardiovascular disease. Diabetes Care 1991, 14(3):173-194

4. Einhorn D: ACE position statement on insulin resistance syndrome. Endocr Pract 2003, 9:237-52.

5. Expert Panel on Detection, Evaluation, and Treatment of High Blood Cholesterol in Adults. Executive summary of the third report of the National Cholesterol Education Program (NCEP) Expert Panel on Detection, Evaluation, and Treatment of High Blood Cholesterol in Adults (Adult Treatment Panel III). JAMA 2001, 285(19):2486-97.

6. Dubose KD, Stewart EE, Charbonneau SR, Mayo MS, Donnelly JE: Prevalence of the metabolic syndrome in elementary school children. Acta Paediatrica 2006, 95(8):1005-1011.

7. Braunschweig CL, Gomez S, Liang H, Tomey K, Doerfler B, Wang Y, Beebe C, Lipton R: Obesity and risk factors for the metabolic syndrome among low-income, urban, African American schoolchildren: the rule rather than the exception? Am J Clin Nutr 2005, 81 (5):970-975.

8. Cook S, Wietzman M, Auinger P, Nguyen M, Dietz WH: Prevalence of a metabolic syndrome phenotype in adolescents: findings from the third National Health and Nutrition Examination Survey, 1988-1994. Arch Pediatr Adolesc Med 2003, 157(8):821-827.

9. Saland JM: Update on the metabolic syndrome in children. Curr Opin Pediatr 2007, 19(2):183-191.

10. Huang TK, Ball GDC, Franks PW: Metabolic syndrome in youth: current issues and challenges. Appl Physio/ Nutr Metab 2007, 32(1):13-22.

11. Cruz ML, Weigensberg MJ, Huang TTK, Ball G, Shaibi GQ, Goran ML: The metabolic syndrome in overweight Hispanic youth and the role of insulinsensitivity. J Clin Endocrinol Metab 2004, 89(1):108-113.

12. López-Capapé M, Alonso M, Colino E, Mustieles C, Corbatón J, Barrio R: Frequency of the metabolic syndrome in obese Spanish pediatric population. Eur J Endocrinol 2006, 155(2):313-9.

13. Druet C, Dabbas M, Baltakse V, Payen C, Jouret B, Baud C, Chevenne D, Ricour C, Tauber M, Polak M, Alberti C, Levy-Marchal C: Insulin resistance and the metabolic syndrome in obese French children. Clin Endocrinol 2006, 64(6):672-8

14. Li Y, Yang X, Zhai F, Piao J, Zhao W, Zhang J, Ma G: Childhood obesity and its health consequence in China. Clin Endocrinol 2008, 9(1):82-86.

15. Ferreira AP, Oliveira CER, França NM: Metabolic syndrome and risk factors for cardiovascular disease in obese children; the relationship with insulin resistance (HOMA-IR). J Pediatr 2007, 83(1):21-26.

16. Silva RCQ, Miranda WL, Chacra AR, Dib AS: Metabolic syndrome and insulin resistance in normal glucose tolerant Brazilian adolescents with family history of type-2 diabetes. Diabetes Care 2005, 28(3):716-718.

17. Souza MSF, Leme RB, Franco RR, Romaldini CC, Tumas R, Cardoso AR, Damiani D: Metabolic syndrome in obese and overweight adolescents. Rev Paul Pediatr 2007, 25(3):214-220.

18. Buff CG, Ramos E, Souza FIS, Sarni ROS: Frequency of metabolic syndrome in overweight and obese children and adolescents. Rev Paul Pediatr 2007, 25(3):221-6.

19. Alberti KG, Zimmet PZ: Definition, diagnosis and classification of diabetes mellitus and its complications. Part 1: Diagnosis and classification of diabetes mellitus. Provisional report of a WHO consultation. Diabet Med 1998, 15(7):539-593.

20. Reinhr T, Sousa G, Toschke AM, Andler W: Comparison of metabolic syndrome prevalence using eight different definitions: a critical approach. Arch Dis Child 2007, 92(12):1067-1072.

21. Golley RK, Magarey AM, Steinbeck KS, Baur LA, Daniels LA: Comparison of metabolic syndrome prevalence using six different definitions in overweight pre-pubertal children enrolled in weight management study. Int J Obes 2006, 30(5):853-860.

22. CDC table for calculated body mass index values for selected heights and weights for ages 2 to 20 years: Developed by the National Center for Health Statistics in collaboration with the National Center for Chronic Disease Prevention and Health Promotion. 2000 [http://www.cdc.gov/ growthcharts].

23. World Health Organization: Physical status: the use and interpretation of anthropometry. Geneva WHO Technical Report Series, 8541995.

24. Slaugther MH, Lohman TG, Boileau RA, Horswill CA, Stillman RJ, van Loan $M D$, Bemben DA: Skinfold equations for estimation of body fatness in children and youth. Hum Biol 1988, 60(5):709-723.

25. Lohman TG: The use of skinfold to estimate body fatness on children and youth. J Phys Educ Recreat Dance 1987, 58(9):98-102.

26. National High Blood Pressure Education Program Working Group on High Blood Pressure in Children and Adolescents: The Fourth Report on the Diagnosis, Evaluation, and Treatment of High Blood Pressure in Children and Adolescents. Pediatrics 2004, 114(2 Suppl 4th Report):555-576.

27. Levy JC, Matthews DR, Hermans MP: Correct Homeostasis Model Assessment (HOMA) Evaluation uses the computer program. Diabetes Care 1998, 21(12):2191-2192

28. Tanner JM: Growth at adolescence: with a general condition of the effects of hereditary and environmental factors upon growth and maturation from birth to maturity Oxford: Blackwell Scientific; 1962.

29. Cohen J: A coefficient of agreement for nominal scales. Educ Psycho Meas 1960, 20(1):37-46.

30. Monzavi R, Dreimane D, Geffner ME, Braun S, Conrad B, Klier M, Kaufman FR: Improvement in risk factors for metabolic syndrome and insulin resistance in overweight youth who are treated with lifestyle intervention. Pediatrics 2006, 117(6):1111-1118.

31. Boney CM, Verma A, Tucker R, Vohr BR: Metabolic syndrome in childhood: association with birth weight, maternal obesity, and gestational diabetes mellitus. Pediatrics 2005, 115(3):290-296.

32. Ferranti SD, Osganian SK: Epidemiology of paediatric metabolic syndrome and type-2 diabetes mellitus. Diabetes Vasc Dis Res 2007, 4(4):285-296.

33. Ford ES, Li C: Defining the metabolic syndrome in children and adolescents: Will the real definition please stand up? J Pediatr 2008, 152(2):160-164

34. De Ferranti SD, Gauvreau K, Ludwig DS, Neufeld EJ, Newburger JW, Rifai N: Prevalence of the metabolic syndrome in American Adolescents. Circulation 2004, 110(16):2494-2497.

35. Viner RM, Segal TY, Lichtarowicz-Krynska E, Hindmarsh P: Prevalence of the insulin resistance syndrome in obesity. Arch Dis Child 2005, 90(1):10-14 
36. Seo SJ, Lee Y, Lee SW: The Prevalence of the Metabolic Syndrome in Korean Children and Adolescents: Comparisons of the Criteria of Cook et al., Cruz and Goran, and Ferranti et al. Yonsei Med J 2008, 49(4):563-572.

37. Brambilla P, Lissau I, Flodmark CE, Moreno LA, Widhalm K, Wabitsch M, Pietrobelli A: Metabolic risk-factor clustering estimation in Children: across pediatric metabolic syndrome. Int J Obes 2007, 31(4):591-600

38. Madeira IR, Noronha C, Carvalho M, Gazolla FM, Matos HJ, Borges MA, Bordallo MAN: Ponto de corte do índice Ponto de Corte do Índice Homeostatic Model Assessment for Insulin Resistance (HOMA-IR) Avaliado pela Curva Receiver Operating Characteristic (ROC) na detecção de síndrome metabólica em crianças pré-púberes com excesso de peso. Ara Bras Endocrino Metab 2008, 52(9):1466-1473.

39. Reaven GM: The metabolic syndrome in children and adolescents: disease or distraction? Pediatric Diabetes 2006, 86:1237-1247.

40. Jones K: The dilema of the metabolic syndrome in children and adolescents: disease or distraction? Pediatric Diabetes 2006, 7(6):311-321.

41. Eisenmann JC: On the use of a continuous metabolic syndrome score in pediatric research. Cardiovasc Diabetol 2008, 7:17

42. Eisenmann JC, Laurson KR, DuBose KD, Smith BK, Donnelly JE: Construct validity of a continuous metabolic syndrome score in children. Diabetology \& Metabolic Syndrome 2010, 2:1-18.

43. Haney EM, Huffman LH, Bougatsos C, Freeman M, Steiner RD, Nelson HD, US Preventive Services Task Force: Screening and treatment for lipid disorders in children and adolescents: Systematic evidence review for the US Preventive Services Task Force. Pediatrics 2007, 120(1):e189-214.

44. Daniels SR, Greer F: Lipid screening and cardiovascular health in childhood. Pediatrics 2008, 122(1):198-208.

45. Pankon JS: Insulin resistance and cardiovascular disease risk factors in children of parents with the insulin resistance (metabolic) syndrome. Diabetes Care 2004, 27(3):775-780.

46. Bosy-Westphal A, Geisler C, Onur S, Korth O, Selberg O, Schrezenmeir J, Muller MJ: Value of body fat mass vs anthropometric obesity indices in the assessment of metabolic risk factors. Int J Obes 2006, 30(3):475-483.

47. Kelishadi R, Gouya MM, Adeli K, Ardalan G, Gheiratmand R, Majdzadeh R, Mahmoud-Arabi MS, Delavari A, Riazi MM, Barekati H, Motaghian M, Shariatinejad K, Heshmat R: Factors associated with the metabolic syndrome in a national sample of youths: CASPIAN Study. Nutrition, Metabolism \& Cardiovascular Disease 2008, 18(7):461-470.

48. Strufaldi MWL, Silva EMK, Puccini RF: Metabolic syndrome among prepubertal Brazilian schoolchildren. Diabetes Vasc Dis Res 2008, 5(4):291-297.

49. Barker DJP, Godfrey KM, Gluckman PD, Harding JE, Owens JA, Robinson JS: Fetal nutrition and cardiovascular disease in adult life. Lancet 1993, 341(8850):938-941.

50. Singhal A, Fewtrell M, Cole TJ, Lucas A: Low nutrient intake and early growth for later insulin resistance in adolescents born preterm. Lancet 2003, 361(9363):108997.

51. Ekelund U, Ong KK, Linné Y, Neovius M, Brage S, Dunger DB, Wareham NJ, Rössner S: Association of weight gain in infancy and early childhood with metabolic risk in young adults. J Clin Endocrinol Metab 2007, 92(1):98-103.

52. Chan DF, Chu WC, Chan MH, Wong EM, Liu EK, Chan IH, Yin J, Lam CW, Fok TF, Nelson EA: Hepatic steatosis in obese Chinese children. Int J Obes Relat Metab Disord 2004, 28:1257-1263.

53. Kelishadi R, Cook SR, Adibi A, Faghihimani Z, Ghatrehsamani S, Beihaghi A, Salehi H, Khavarian N, Poursafa P: Association of the components of the metabolic syndrome with non- alcoholic fatty liver disease among normal-weight, overweight and obese children and adolescents. Diabetology \& Metabolic Syndrome 2010, 1:29.

54. Pellanda LC, Echenique L, Barcellos LMA, Maccari J, Borges FK, Zen BL: Ischemic heart disease: prevention should begin in childhood. J Pediatr (Rio J) 2002, 78(2):91-6.

55. Roberts EA: Non-alcoholic fatty liver disease (NAFLD) in children. Front Biosci 2005, 10:2306-2318.

doi: 10.1186/1758-5996-2-39

Cite this article as: Rinaldi et al., Metabolic syndrome in overweight children from the city of Botucatu - São Paulo State - Brazil: agreement among six diagnostic criteria Diabetology \& Metabolic Syndrome 2010, 2:39

\section{Submit your next manuscript to BioMed Centra and take full advantage of:}

- Convenient online submission

- Thorough peer review

- No space constraints or color figure charges

- Immediate publication on acceptance

- Inclusion in PubMed, CAS, Scopus and Google Scholar

- Research which is freely available for redistribution

Submit your manuscript at www.biomedcentral.com/submit
C Biomed Central 